\title{
Institucionalização e expansão da História Oral: dez anos de IOHA
}

\author{
Marieta de Moraes Ferreira*
}

\section{Introdução}

A proposta deste artigo é acompanhar o processo de institucionalização da História Oral, que se concretizou plenamente em 1996, com a criação da Associação Internacional de História Oral (IOHA - International Oral History Association). A idéia básica é analisar o impacto da entidade para a ampliação e diversificação deste campo de pesquisa, e fazer um balanço do seu papel após uma década de existência. Partimos do princípio que a IOHA tem sido não só um veículo de renovação e dinamização da História Oral, mas também um canal que possibilita a emergência de novos desafios e caminhos a serem percorridos.

\section{A Pré-História da Associação Internacional de História Oral}

A reintrodução da fonte oral, sobretudo a partir da segunda metade do século XX, ${ }^{1}$ não foi imediatamente aceita pela comunidade acadêmica. Os adeptos da história oral permaneceram à margem das instituições de pesquisa e acabaram por se organizar em grupos particulares com suas próprias instituições, sociedades, revistas e colóquios.

* Professora do Departamento de História do Instituto de Filosofia e Ciências Sociais da Universidade Federal do Rio de Janeiro-IFCS/UFRJ. Presidente da Associação Brasileira de História Oral-ABHO $(1994 / 96)$ e da International Oral History Association-IOHA (2000/2002).

1 Philippe Joutard esclarece que a história africana, desde sua origem, utilizou fontes orais. Sobre a história oral no século XX ver: JOUTARD, 1996; TREBITSCH, 1994; VILANOVA, 2002. 
Na década de 1950, nos Estados Unidos, uma primeira geração de pesquisadores se dedicou à coleta de depoimentos orais mediante a utilização de um gravador. O objetivo era desenvolver um programa de entrevistas voltado para a preservação de informações acerca de grupos dominantes norte-americanos. Esse programa veio a constituir o Columbia Oral History Office, organismo que servia de modelo para outros centros criados nos anos 1950 em bibliotecas e arquivos, no Texas, Berkeley e Los Angeles. Esse primeiro ciclo de expansão do que se chamou de história oral se atribuiu a tarefa de preencher as lacunas do registro escrito por meio da formação de arquivos de fitas transcritas.

Ainda nessa primeira fase, podem ser mencionados outros exemplos de projetos de recolhimento de depoimentos, como o do Comitê de História da Segunda Guerra Mundial, na França, e os arquivos sonoros do Instituto Nacional de Antropologia (1956), do México, que recolhiam as memórias dos chefes da Revolução Mexicana. $\mathrm{Na}$ Itália, sociólogos e antropólogos próximos a partidos políticos de esquerda, também passaram a utilizar a investigação oral para estudar a cultura popular.

A partir dos anos 1960, uma nova geração assumia um conceito mais ambicioso, negando a visão dos relatos orais como fontes complementares aos materiais escritos. Nos EUA, a luta pelos direitos civis, travada pelas minorias de negros, mulheres imigrantes, etc., faria destas as principais responsáveis pela afirmação da história oral, que procurava dar vOz aos excluídos, recuperar a trajetória dos grupos dominados, retirar do esquecimento o que a história oficial sufocara por tanto tempo. A história oral se firmava assim como um instrumento de construção de identidade de grupos e de transformação social: era uma história oral militante. Essa proposta, no entanto não teve boa acolhida entre a comunidade acadêmica e menos ainda entre os historiadores.

Nesse período, a ampliação da história oral ocorreu em paralelo aos inconformismos que sacudiram a década, como os movimentos de 1968. As vertentes mais radicais defendiam uma história alternativa, não somente em relação à academia, mas também em relação a todas as construções historiográficas baseadas no escrito. A idéia do testemunho oral como genuína "verdade do povo" assumia então uma dimensão política de defesa aos historicamente oprimidos. Como desdobramento desse movimento, em 1966 foi fundada a American Oral History Association e a Oral History Association Newsletter começou a circular no ano seguinte. Em 1973 
foi lançada a Oral History Review. Em 1975, Ronald Grele, em seu livro Envelopes of Sounds, propôs uma solução de compromisso reivindicando a afirmação de uma história oral universitária, porém voltada para a trajetória dos excluídos.

Essa idéia de uma história oral dos excluídos expandiu-se para outros países, ganhando adeptos na Inglaterra, onde foram criadas a revista Oral History Review, em Essex, e a Oral History Society em 1973. A publicação da obra de Paul Thompson, The Voice of Past, em 1978, aprofundou a idéia de que a história oral tem por função devolver a história do povo, promover a democratização da história em si mesma. Portanto, deveria se firmar como uma contra-história, operando uma inversão radical nos métodos e objetos consagrados. Deveria ser uma história militante e politicamente engajada. O uso e a discussão da história oral expandiu-se para outros países como Alemanha, Itália, França e Espanha, assumindo em cada região características e marcas decorrentes da cultura historiográfica local. A despeito das desconfianças, o movimento da história oral tendeu a se ampliar nos meios acadêmicos europeus com os estudos de Paul Thompson na Inglaterra, de Luiza Paserini e de Alessandro Portelli na Itália, de Mercedes Vilanova na Espanha e de Lutz Niethammer na Alemanha.

É nesse contexto de debates acerca dos usos da história oral, que em 1975, no XIV Congresso Internacional de Ciências Históricas em São Francisco, Estados Unidos, foi organizada a mesa-redonda: "História Oral: uma nova metodologia para a pesquisa histórica". Essa iniciativa representou um marco importante na medida que colocou na agenda de discussões do mais importante evento internacional da comunidade dos historiadores a inevitabilidade da aceitação da História Oral. No ano seguinte, em 1976, realizou-se em Bolonha, na Itália, a I Conferência Internacional de História Oral, com o título de "Antropologia e História: fontes orais". Esses dois eventos podem ser apontados como pontos de partida para a inauguração de um terceiro momento da história oral, que se caracterizou pela criação de uma primeira rede institucionalizada de pesquisadores de diferentes países, em torno do movimento da história oral.

Nos anos seguintes, um grupo de pesquisadores e professores europeus e norte-americanos passou a organizar conferências periódicas que se constituíam em espaços para apresentação e discussão de suas experiências de pesquisa, bem como refletir sobre questões metodológicas inerentes ao campo da História Oral. Esses eventos internacionais 
estimularam a criação de uma rede de profissionais vinculados à história oral e o surgimento de núcleos de pesquisa ligados às universidades, bem como de revistas especializadas que procuravam congregar pesquisadores de diversas localidades.

No Brasil,, já em 1975 a Fundação Getulio Vargas criou o primeiro programa de história oral destinado a coletar os testemunhos dos líderes políticos brasileiros. Em 1981, na Itália, foi criada a revista Fonti orale, que durou até 1987. Em 1980, na França, criou-se a Associação Francesa de Arquivos Sonoros e realizou-se, no Instituto de História do Tempo Presente, o primeiro encontro francês de investigadores que utilizavam fontes orais.

De maneira geral, a partir de 1975, o movimento de história oral espraiou-se pelos centros de pesquisa do mundo e consolidou-se como campo investigativo. Essa terceira fase da história oral pode ser considerada como um período de disseminação e amadurecimento de centros de pesquisa e publicações, não obstante as conferências internacionais ainda se mantivessem circunscritas a um pequeno grupo de pesquisadores, com forte presença de europeus. A listagem das oito primeiras conferências indica a sua concentração na Europa e a ausência de regularidade temporal dos eventos (ver quadro à página seguinte). Merece ser destacado que durante os primeiros 20 anos, desde a primeira conferência em 1976, a idéia de criação de uma entidade que agregasse aqueles que trabalhavam no campo e institucionalizasse o movimento internacional de História Oral não foi adiante.

A dificuldade de acesso ao material das conferências internacionais não nos permite trabalhar de forma mais detalhada os perfis desses encontros. No entanto, a consulta aos proceedings da XVII Conferência Internacional (Siena International Oral History Conference, "Memory and multiculturalism", Siena-Lucca, 25-28 february 1993), realizada em 1993, revela a presença maciça de pesquisadores europeus ${ }^{3}(66 \%)$, seguida de longe pela América do Norte (15\%), América Latina (14\%), Oceania (4\%) e Ásia (1\%).

\footnotetext{
Sobre a História Oral no Brasil ver: FERREIRA, 1998; FERREIRA, 2001.

3 O total de textos publicados em Siena foi de 97, contudo, foi possível certificar a origem institucional de 72 trabalhos.
} 


\begin{tabular}{|c|l|}
\hline Ano & $\begin{array}{l}\text { Título do Evento } \\
\text { Localidade - País }\end{array}$ \\
\hline 1975 & $\begin{array}{l}\text { XIV Congresso Internacional de Ciências Históricas } \\
\text { São Francisco - Estados Unidos }\end{array}$ \\
\hline 1976 & $\begin{array}{l}\text { I Conferência Internacional de História Oral } \\
\text { Bolonha - Itália }\end{array}$ \\
\hline 1978 & $\begin{array}{l}\text { II Conferência Internacional de História Oral } \\
\text { Colchester - Inglaterra }\end{array}$ \\
\hline 1980 & $\begin{array}{l}\text { III Conferência Internacional de História Oral } \\
\text { Amsterdã - Holanda }\end{array}$ \\
\hline 1982 & $\begin{array}{l}\text { IV Conferência Internacional de História Oral } \\
\text { Aix-en-Provence - França }\end{array}$ \\
\hline 1985 & $\begin{array}{l}\text { V Conferência Internacional de História Oral } \\
\text { Barcelona - Espanha }\end{array}$ \\
\hline 1987 & $\begin{array}{l}\text { VI Conferência Internacional de História Oral } \\
\text { Oxford - Inglaterra }\end{array}$ \\
\hline 1990 & $\begin{array}{l}\text { VII Conferência Internacional de História Oral } \\
\text { Essen - Alemanha }\end{array}$ \\
\hline 1993 & $\begin{array}{l}\text { VIII Conferência Internacional de História Oral } \\
\text { Siena - Itália }\end{array}$ \\
\hline
\end{tabular}

Pode-se destacar o sucesso dos congressos internacionais como elemento central para o estabelecimento da história oral no mundo acadêmico. Outro ponto marcante decorrente das conferências internacionais foi o aumento do número de publicações especializadas e o surgimento de congressos regionais e nacionais. Em 1989, o surgimento da revista Historia y Fuente Oral dirigida desde o princípio por Mercedes Vilanova funcionou como elemento aglutinador, verdadeiro ponto de referência não só para os estudos de história oral espanhola, como também para o conjunto da comunidade internacional.

Ao longo da década de 1980 registraram-se transformações expressivas nos diferentes campos da pesquisa histórica: incorporou-se o estudo 
dos temas contemporâneos, revalorizou-se a análise qualitativa, resgatouse a importância das experiências individuais, ou seja, houve um deslocamento do interesses das estruturas para as redes, dos sistemas de posições para as situações vividas, das normas coletivas para as situações singulares. Paralelamente, a história cultural ganhou novo impulso e ocorreu um renascimento do estudo do político.

O resgate do político, como um lócus privilegiado de articulação do todo social, trouxe à tona alternativas importantes para revalorização da ação dos atores e de suas estratégias, bem como o papel dos sujeitos na história. Dentro dessa nova postura, foram atribuídos novos significados aos depoimentos, relatos pessoais e biografias. Estas transformações ocorridas no campo da história em geral, e na história do século XX em particular, geraram uma nova discussão sobre o papel das fontes históricas, permitindo que a história oral ocupe um novo espaço nos debates historiográficos atuais.

A emergência da história do século XX com um novo estatuto, definido por alguns como história do tempo presente, portanto portadora da singularidade de conviver com testemunhos vivos que sob certo aspecto condicionam o trabalho do historiador, coloca obrigatoriamente em foco os depoimentos orais. Além disso, as próprias transformações das sociedades modernas e as conseqüentes mudanças no conteúdo dos arquivos, que cada vez mais passam a dispor de registros sonoros, impulsionaram a tendência a uma revisão do papel das fontes escritas e orais.

As drásticas e aceleradas mudanças nas sociedades contemporâneas geram movimentos sociais majoritariamente fragmentados, locais, com objetivos específicos e efêmeros. Nesse contexto, as pessoas tendem a reagrupar-se em torno de identidades primárias (religiosas, étnicas, territoriais, nacionais) como forma de lidar com a diluição de fronteiras e a fragilização das tradições e dos laços interpessoais.

Essa busca desenfreada pela identidade é a fonte principal de significado em um período histórico caracterizado pela ampla desestruturação das organizações, deslegitimação das instituições, enfraquecimento de importantes movimentos sociais e emergência de expressões culturais efêmeras.

A aceleração do tempo e a preocupação com a perda de sentido do passado e com o aumento da capacidade de esquecer têm levado as sociedades contemporâneas a demonstrar grande interesse em recuperar a 
memória e também a história. Talvez seja essa a contrapartida de um processo de globalização que vem transformando visões de mundo e comportamento, acelerando o tempo da história e produzindo, enfim, um sentimento de insegurança. Voltar às origens significaria reconstituir o trajeto percorrido para definir o rumo da viagem.

Essas novas circunstâncias, ao longo dos anos 1990, iriam estimular uma nova geração de pesquisadores a intensificar seus interesses no uso da história oral e buscar uma maior participação nas conferências internacionais de história oral.

\section{A Conferência Internacional de Nova York em 1994: um divisor de águas}

Ao longo de quase duas décadas foram realizados oito congressos internacionais, concentrados na Europa. Esses encontros, conforme já assinalamos, desenvolveram de forma expressiva o campo de História Oral, diversificando abordagens, produzindo debates metodológicos e principalmente influenciando uma nova geração de pesquisadores dos chamados países em desenvolvimento.

A conferência organizada por Ronald Grele na Universidade de Columbia, Nova York, sem numeração e que não produziu proceedings que pudessem guiar nossa pesquisa, representou um início de novos tempos e começou abrir um diálogo maior com os países fora do eixo EuropaEUA, e em especial com os latino-americanos.

O encontro promovido em Columbia representou um novo momento para a história oral, abrindo espaço para a participação de uma nova geração de pesquisadores e para a emergência de novas trocas e especialmente um espaço de socialização entre os pais fundadores de história oral e os jovens pesquisadores.

A partir desse encontro foram abertos novos caminhos para a criação de uma nova rede de intercâmbios internacionais. No caso específico do Brasil, que pode ser tomado como exemplo para avaliarmos a influência da conferência organizada por Grele, detecta-se um aumento significativo da presença de seus pesquisadores e um momento importante para o estabelecimento de contatos que tiveram inúmeros desdobramentos posteriores. Deve ser lembrado que em abril de 1994 já havia sido criada 
a Associação Brasileira de História Oral, que passou a funcionar como um espaço de aglutinação, não só de brasileiros, mas também para a articulação de pesquisadores de outros países latino-americanos com vistas à criação de associações de História Oral e para o estreitamento de contatos com pesquisadores estrangeiros renomados como Mercedes Vilanova e Phillipe Joutard. No entanto, em Nova York, era a primeira vez que um número expressivo de jovens pesquisadores apresentava seus trabalhos e estabelecia os contatos para trocas regulares (No ano seguinte, em 1995, vieram pela primeira vez ao Brasil Alessandro Portelli, Mary Marshal Clark, Lutz Nutheremer e Alistair Thompson para o encontro "Ética e Historia Oral”. Em 1996, em Campinas, o III Encontro Nacional de História Oral contou com a participação de Ronald Grele, Alice Bongil [México], Henrique Rosseau [França]). Essa nova onda de contatos detectada no caso brasileiro também pode se percebida em outros países periféricos, o que por sua vez estimulava a emergência de um clima para finalmente ser formalizada a criação de uma associação internacional. Várias associações nacionais já tinham sido criadas e esses exemplos funcionaram como estímulo.

\section{A criação da IOHA}

Em 1996 foi organizada a IX Conferência Internacional de Historia Oral, em Gotemburgo, na Suécia, que já indicava que novos ventos estavam soprando e que novas articulações políticas estavam sendo esboçadas. A ampliação do número de participantes e a forte presença de latino-americanos, especialmente brasileiros, pressionava por uma maior participação na nova entidade a ser criada. O encontro de Gotemburgo contou com 164 trabalhos aprovados, dos quais 22 eram de origem brasileira, 20 eram ingleses e 15 finlandeses (IX International Oral History Conference, "Communicating Experience", Sweden, 1996), conforme indica o quadro adiante. $^{4}$

4 Todas as informações sobre número e origem institucional dos participantes foram retiradas dos anais dos eventos ocorridos de 1993-2004. O evento de 1994 (Nova York) não produziu anais. Os dados sobre a conferência na Austrália foram retirados do site oficial do evento: http://www.une.edu.au/ ioha2006/conference\%20program.html Acesso em 20/06/2006. 


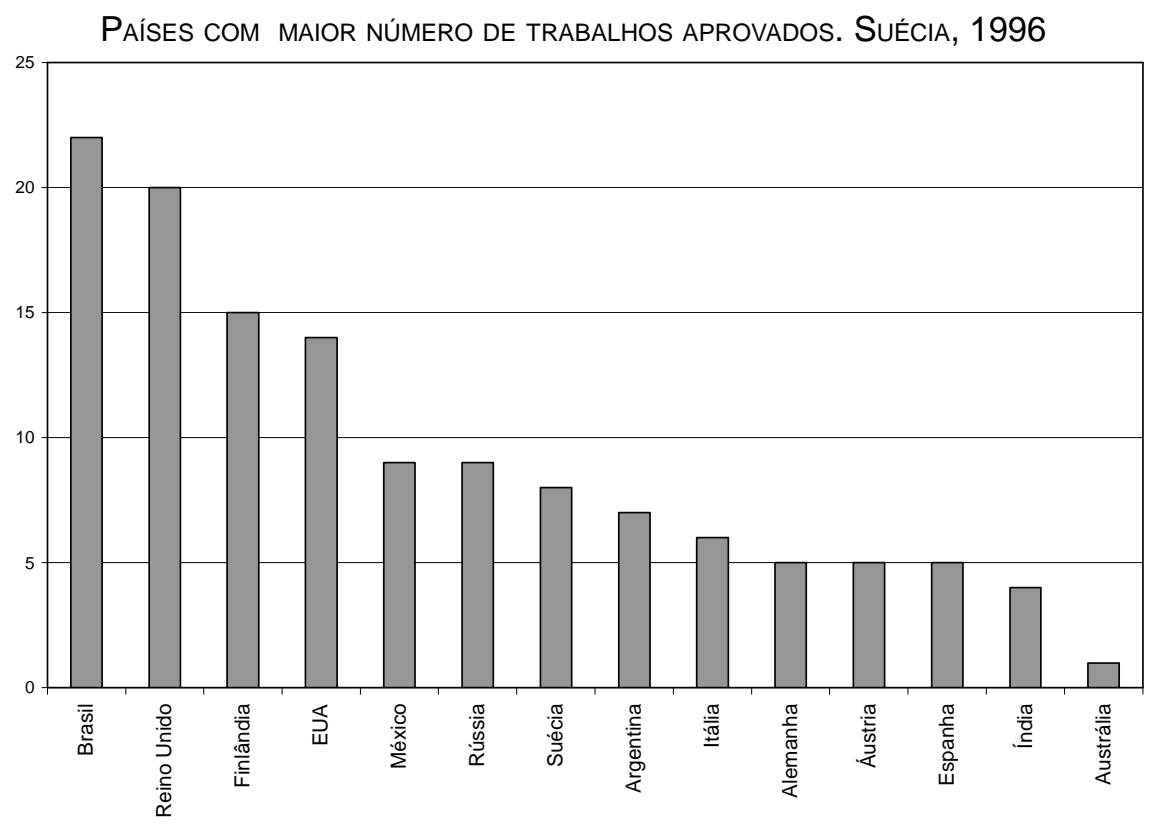

Ao fim do encontro foi fundada a Associação Internacional de História Oral - IOHA, tendo sido eleita como sua primeira presidente Mercedes Vilanova, e sendo escolhido o Brasil como local para a próxima conferência, a ser realizada em 1998, no Rio de Janeiro. Nos estatutos aprovados ficava definida a representação por continente, a periodicidade e rotatividade continental dos encontros e o estabelecimento do espanhol e do inglês como línguas oficiais da associação. Com a formalização da IOHA, o processo de institucionalização do movimento de historia oral estava consolidado e estava aberto o caminho para a ampliação do mapa dos encontros. A limitação geográfica ao eixo Europa - Estados Unidos, berço da história oral e por isso mesmo área dos primeiros encontros, tendia a limitar a participação dos pesquisadores oriundos de países da Ásia, África, Oceania e América Latina nos encontros internacionais. Foi essa percepção, ao lado da maior institucionalização, que permitiu expandir o raio dos encontros e democratizar o campo de trabalho. 


\section{As Conferências Internacionais da IOHA}

Nos dez anos seguintes, a IOHA manteve o compromisso da alternância de países e continentes para realizar seus encontros internacionais. Assim foram realizadas, a seguir, as conferências no Brasil, Turquia, África do Sul, Itália e Austrália, conforme indica a tabela adiante.

\begin{tabular}{|c|l|}
\hline Ano & $\begin{array}{l}\text { Título do Evento } \\
\text { Localidade - País }\end{array}$ \\
\hline 1996 & $\begin{array}{l}\text { IX International Oral History Conference } \\
\text { Gotemburgo - Suécia }\end{array}$ \\
\hline 1998 & $\begin{array}{l}\text { X International Oral History Conference } \\
\text { Rio de Janeiro - Brasil }\end{array}$ \\
\hline 2000 & $\begin{array}{l}\text { XI International Oral History Conference } \\
\text { Istambul - Turquia }\end{array}$ \\
\hline 2002 & $\begin{array}{l}\text { XII International Oral History Conference } \\
\text { Pietermaritzburg - África do Sul }\end{array}$ \\
\hline 2004 & $\begin{array}{l}\text { XIII International Oral History Conference } \\
\text { Roma - Itália }\end{array}$ \\
\hline 2006 & $\begin{array}{l}\text { XIV International Oral History Conference } \\
\text { Sydney - Austrália }\end{array}$ \\
\hline
\end{tabular}

A consulta dos Anais do X Conferência Internacional, realizada no Rio de Janeiro, primeiro encontro fora da Europa e dos EUA e após a criação da IOHA já permite visualizar as transformações (X International Oral History Conference, "Oral History: Challenges for the 21st century", Brazil, 1998), conforme indica o gráfico à página seguinte.

Foram apresentadas 179 comunicações, das quais 124 eram latinoamericanas - 85 eram trabalhos brasileiros, seguidos pela Argentina com 19 e o México com 13. Esses dados demonstram que a realização das conferências internacionais se constitui num estímulo para que a comunidade local de participantes amplie sua atuação, com a produção de novos 
projetos e trabalhos e sua participação no debate internacional. As cidades e países que hospedam esses eventos podem se transformar em novos pólos de divulgação da Historia Oral. Por outro lado, o contato com novas temáticas regionais também enriquece os pesquisadores de fora, intensificando as trocas e intercâmbios. Neste caso particular, a transformação do espanhol com status equivalente ao inglês, certamente foi um veículo de extraordinário estímulo para os latino-americanos.

Países com maior número de trabalhos aprovados. Brasil, 1998

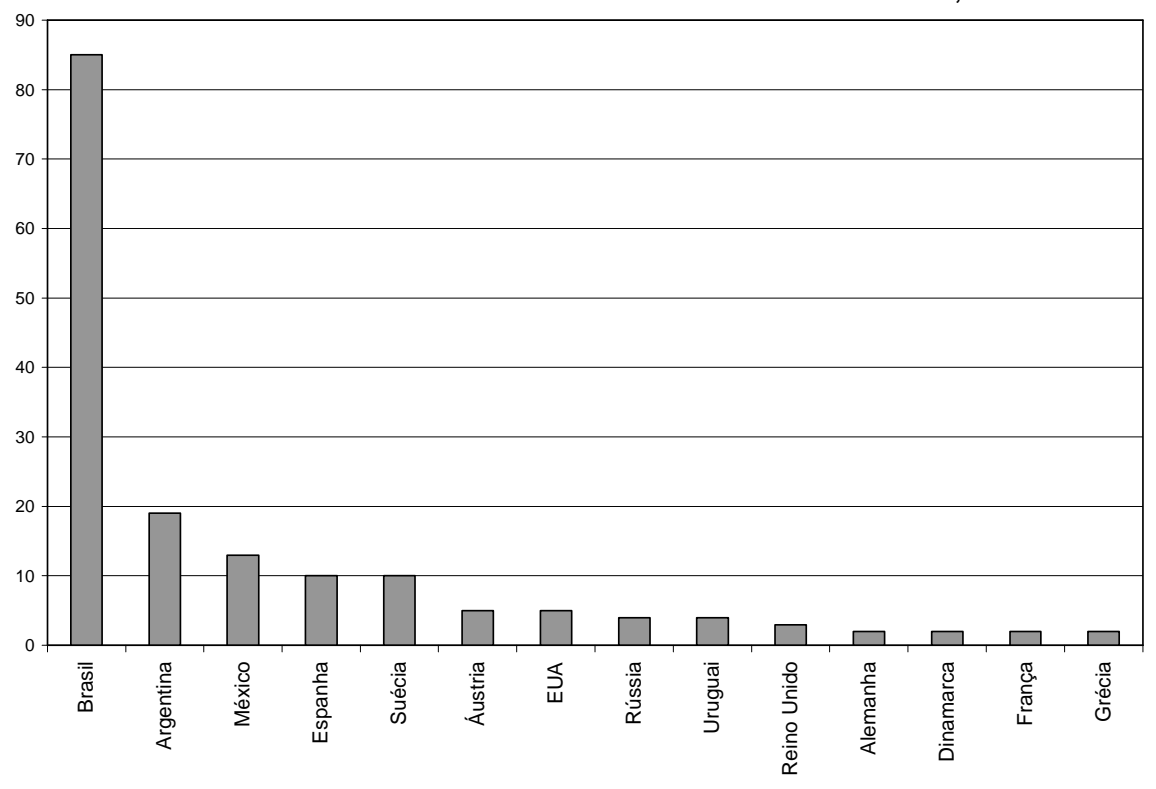

A XI conferência, realizada em Istambul, confirma o crescente número de participantes que a história oral foi angariando ao longo dos anos. O encontro de 2002 contou com 214 trabalhos, no entanto, não foi possível identificar nos proceedings do encontro em Istambul a procedência dos participantes (XI International Oral History Conference, "Crossroads of History: Experience, memory, orality”, Turkey, 2000). Para este evento, a análise sobre a origem das instituições ficou comprometida. 
O deslocamento para África do Sul da XII Conferência, ainda que tenha contado com um número menor de participantes, com aprovação de 154 trabalhos - destes, 46 eram do Brasil, 20 dos Estados Unidos, 15 da Argentina, seguida de perto pela África do Sul com 14 trabalhos - teve um significado importante de promover a incorporação dos países africanos na rede internacional de história oral. Depois deste evento, a África do Sul, por exemplo, que, antes de 2002 tinha pouca representatividade nos congressos internacionais, passou a contar com pesquisadores presentes nas conferências da IOHA (XII Internacional Oral History Conference, "The power of Oral History - Memory, Healing and Development", South Africa, 2002).

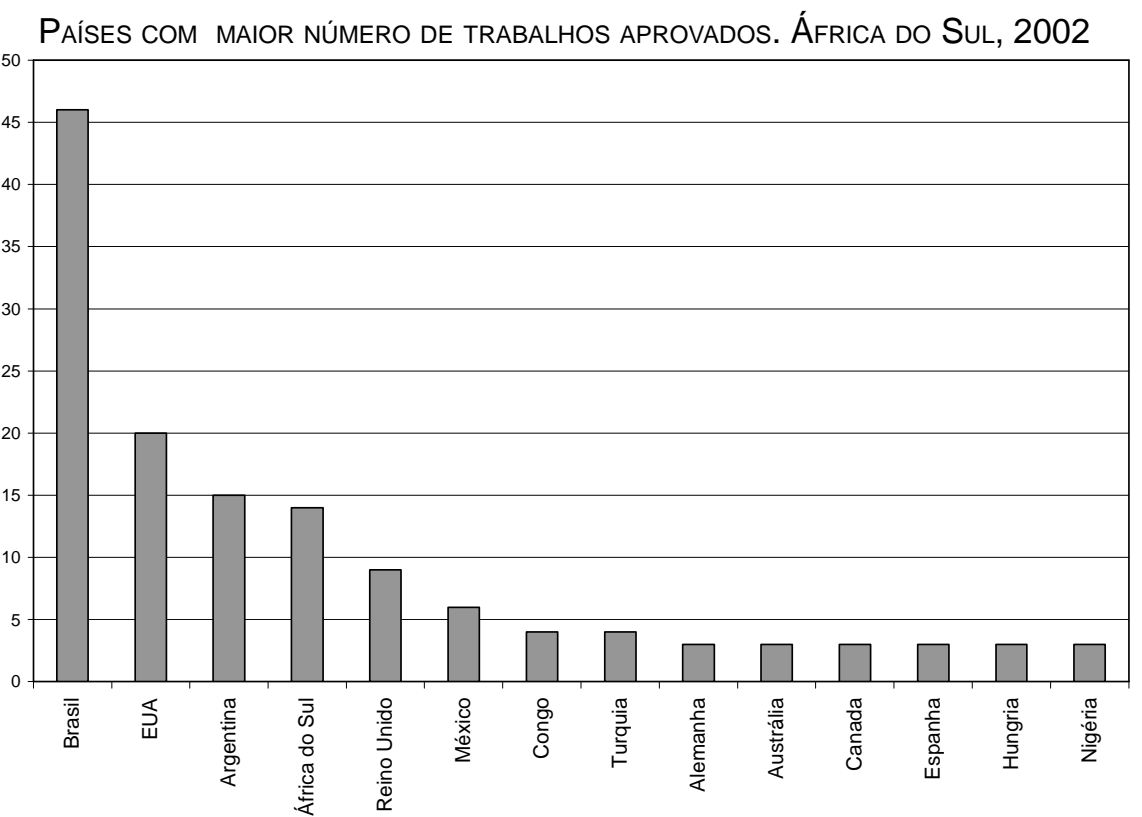


O XIII encontro, realizado em Roma, indica um crescimento expressivo do número de trabalhos (302 trabalhos) e confirma a diversificação de origem dos participantes. Os países como maior número de pesquisadores foram Estados Unidos com 79, Brasil com 73, Grã-Bretanha e Itália, ambos com 17 comunicações (XIII International Oral History Conference, "Memory and Globalization", Italy, 2004).

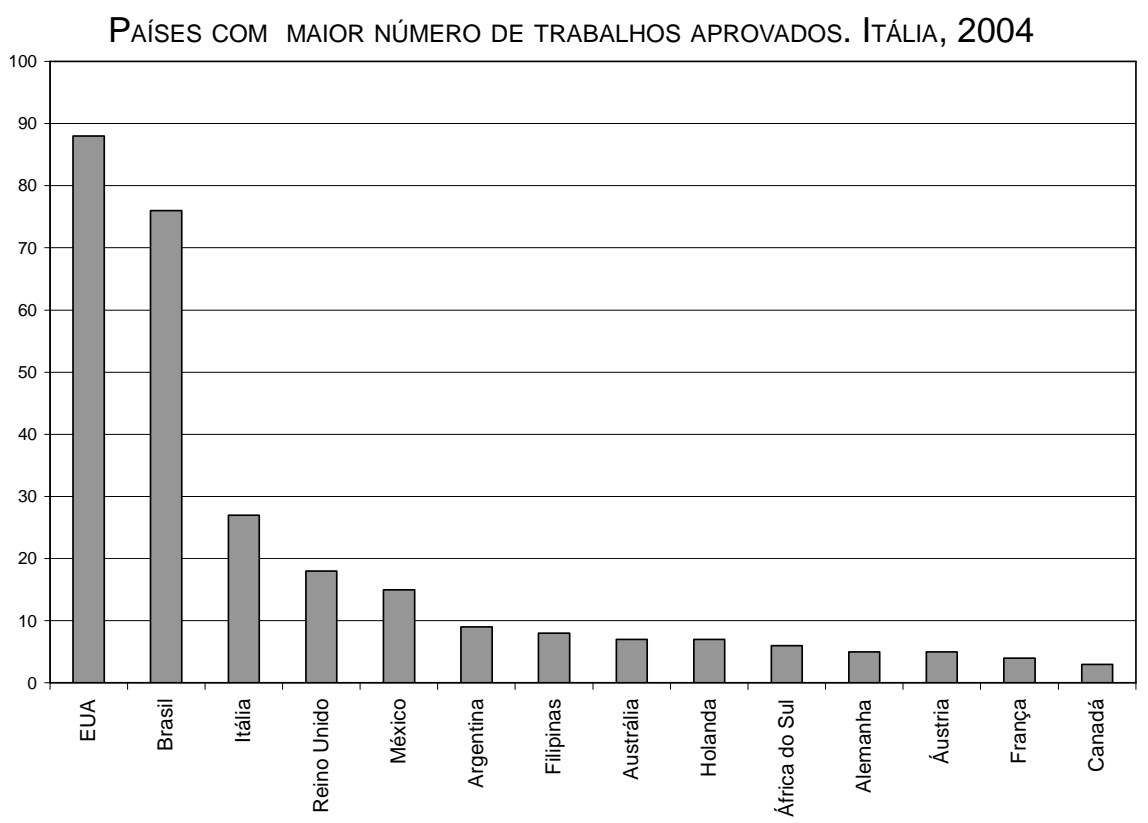


A XIV Conferência internacional, realizada na Austrália em 2006, tem também por mérito o incentivo de pesquisas em História Oral na Oceania. Conta com 203 papers, ${ }^{5}$ dos quais 60 provêm da Austrália, 30 dos Estados Unidos e 17 do Brasil (ver gráfico à página seguinte). Mais uma vez constata-se como o deslocamento geográfico funciona como elemento estimulador para os grupos locais ampliarem sua participação, seja pelas facilidades de proximidade espacial, seja dinamização das redes de pesquisa e a possibilidade de divulgação de seus trabalhos num circuito internacional.

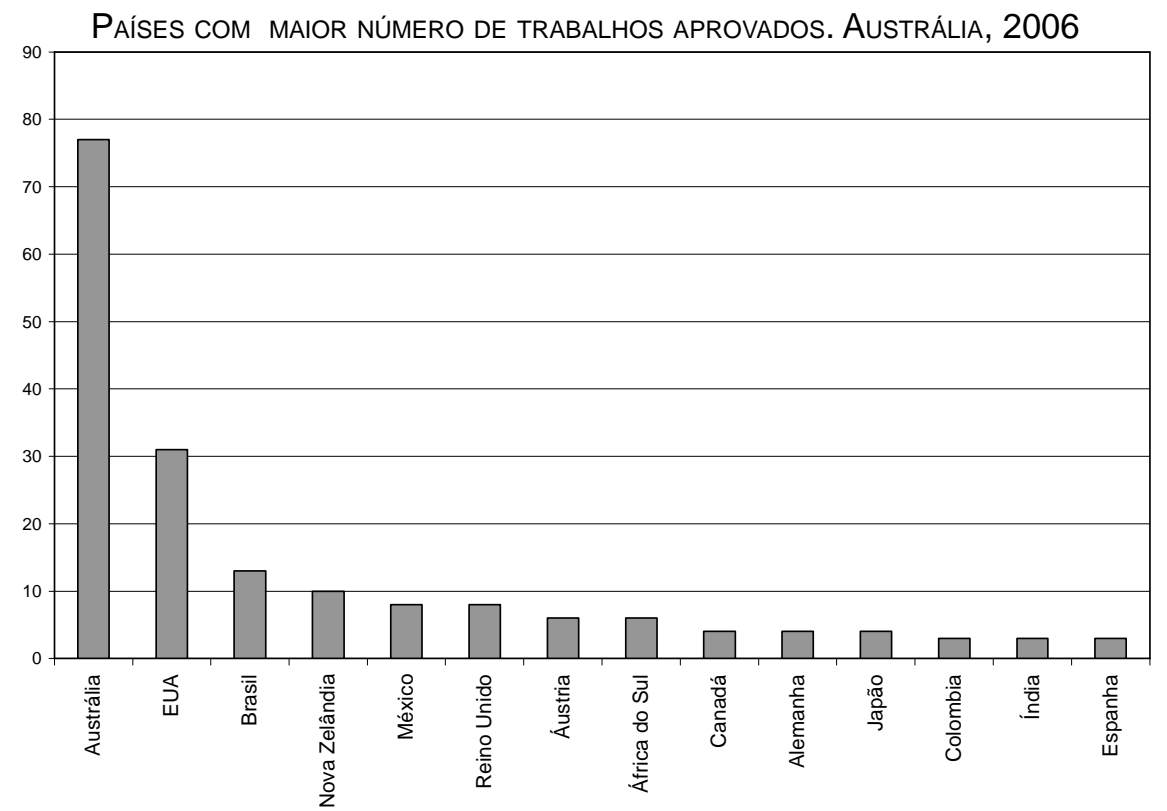

Os quadros a seguir nos permitem perceber como ao longo desses 10 anos foi crescente o número de participantes nos encontros, e como foi ampliado o raio de ação da IOHA, com a realização de conferências internacionais em 5 países, de diferentes continentes: Brasil, Turquia, África do Sul, Itália e Austrália

5 Consulta feita no site do evento em 26/06/2006. http://129.180.101.119/fmi/iwp/cgi?-db=IOHA 2006DB\&-loadframes 

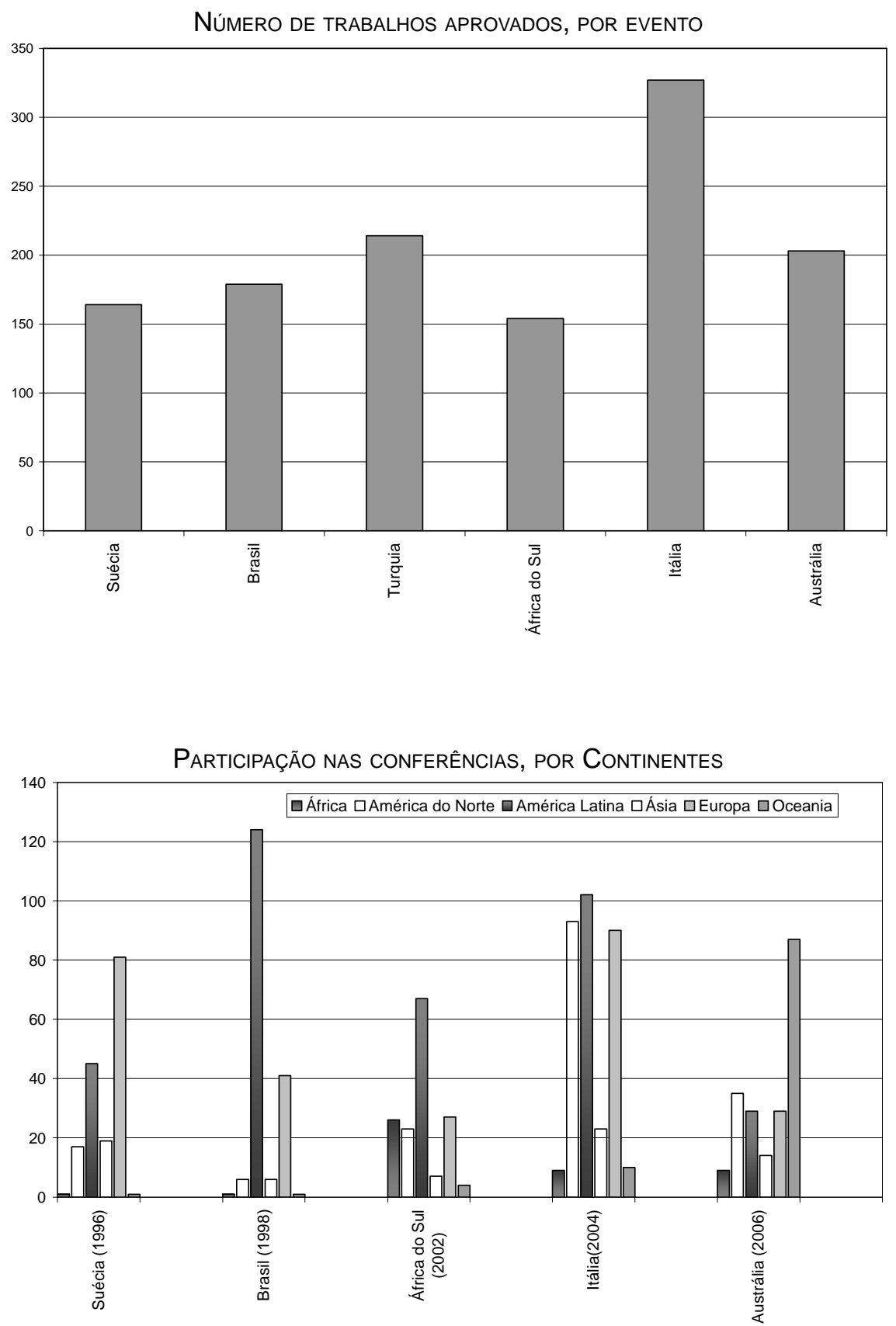
A dinamização espacial é seguida pela ampliação dos temas, um efeito que também tem, em parte, origem no desenvolvimento de temáticas regionais. Não obstante a organização em grupos de trabalho dependa das comissões organizadoras, observa-se que, ao longo de dez anos de IOHA, os trabalhos tenderam à verticalização de temas, setorizando de forma significativa as múltiplas temáticas. Um olhar sobre a expansão da diversidade de assuntos mostrada nos diferentes encontros nos permite apontar superficialmente como temáticas como educação, imigração, traumas, arquivos e acervos, para citar apenas algumas, tornaram-se permanentes e dominantes ao longo dos anos.

\section{Considerações finais}

Um balanço da atuação dos dez anos da IOHA nos permite dizer que um caminho importante foi percorrido com a ampliação do número de participantes, com a diversificação das temáticas, e com a pluralidade de abordagens de história oral, garantindo uma convivência profícua entre perspectivas mais voltadas para trabalhos de intervenção social políticas e projetos de caráter estritamente acadêmicos.

\section{Referências bibliográficas}

FERREIRA, Marieta de Moraes. Desafios e dilemas da história oral nos anos 90: o caso do Brasil. História Oral, São Paulo, n. 1, p. 19-30, 1998.

. Entrevista concedida a Marco Aurélio Santana e Verena Alberti, em 17/06/2000. História Oral, São Paulo, n. 4, p.165-176, 2001.

GRELE, Ronald J. Envelopes of sound. The art of the oral bistory. 2. ed. New York: Praeger, 1991.

JOUTARD, Philippe. 25 años de Historia Oral - II, La historia oral: balance de un cuarto de siglo de reflexión metodológica y de trabajos Historia, Antropología y Fuentes Orales, v. 1, n. 15, p. 155-170, 1996.

PROCEEDINGS of the VIIIth International Oral History Conference, "Memory and multiculturalism". Sienna-Lucca, 25-28 Feb., 1993. Comitato Internazionale di Storia Orale; Amministrazione Provinciale di Lucca, Assessorato alla Cultura; Amministrazione Provinciale di Siena, Assessorato alla Cultura; Regione Toscana; Università degli Studi di Siena. $1 \mathrm{v}$. 
PROCEEDINGS of the IXth International Oral History Conference, "Communicating Experience", 1996. Göteborg, 4 v.

PROCEEDINGS of the Xth International Oral History Conference, "Challenges for the $21^{\text {st }}$ Century", 14-18 July, 1998. Rio de Janeiro: Centro de Pesquisa e Documentação de História Contemporânea do Brasil, Fundação Getulio Vargas: FIOCRUZ, Casa de Oswaldo Cruz, 1998, 3v.

PROCEEDINGS of the XIth International Oral History Conference, "Crossroads of History: Experience, Memory, Orality”, 15-19 July, 2000. International Oral History Association in collaboration with the Department of History at Bogaziçi University; Istanbul: Turkey, 3 v.

PROCEEDINGS of the XIIth International Oral History Conference, "The power of Oral History: Memory, Healing and Development", 24-27 June 2002. Edited by Philippe Denis and James Worthington. The International Oral History Association in collaboration with Sinomlando Project, University of Natal, Pietermaritzburg. 4v.

PROCEEDINGS of the XIIIth International Oral History Conference, "Memory and Globalization”, 23-26 June, 2004. International Oral History Association; Roma, CD-ROM.

PROCEEDINGS of the XIVth International Oral History Conference, "Dancing with memory: oral history and its audiences", 12-16 July, 2006. International Oral History Association; Australia, CD-ROM.

THOMPSON, Paul. The voice of the past. Oxford: Oxford University Press, 1978.

TREBITSCH, Michel. A função epistemológica e ideológica no discurso da história contemporânea In: FERREIRA, Marieta de Moraes (Org.). História oral e multidisciplinaridade. Rio de Janeiro: Diadorim, 1994. p. 19-43.

VILANOVA, Mercedes. How did the IOHA come into being: from Götemborg to Istanbul. Words and Silences - Bulletin of the International Oral History Association, v. 1, n. 1, p. 15-21, 23-29, June 2002.

Resumo: Este artigo visa acompanhar o processo de institucionalização da História Oral, que se concretizou plenamente em 1996 com a criação da Associação Internacional de História Oral (IOHA). Busca-se analisar o impacto da nova entidade para a ampliação e diversificação deste campo de pesquisa, tomando o aniversário de 10 anos da IOHA como um momento de reflexão e balanço do seu papel como veículo de renovação e dinamização da História Oral.

Palavras-chave: Associação Internacional de História Oral; historiografia.

\section{Institutionalization and Expansion of Oral History: Ten Years of IOHA}

Abstract: This article intends to describe the Oral History institutionalization process, which was fully established in 1996 with the creation of the International Oral History Association (IOHA). It analyzes the impact of the new entity on the expansion and diversification of this field of research, using IOHA's $10^{\text {th }}$ anniversary as a moment of reflection and assessment of its role as a vehicle for renewing and dynamizing Oral History.

Keywords: International Oral History Assotiation; historiography. 


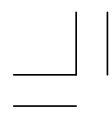

L 